\title{
CERTIFICACIÓN DE COMPETENCIAS
}

Luis Carlos Taborda R.*

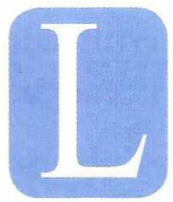

a dinámica del mundo contemporáneo, en lo que al trabajo se refiere, ha introducido el tema de las competencias como el indicador fundamental del desempeño de las personas en un campo determinado. Entendidas en términos generales como el conjunto de capacidades, conocimientos, habilidades y destrezas que nos permite desarrollar eficazmente un trabajo y solucionar problemas, se han convertido en uno de los horizontes de sentido de los procesos educativos.

En este trayecto de educar para adquirir competencias, el sector productivo ha impulsado una serie de mecanismos para comprobar esos desarrollos. Uno de ellos es la certificación. Consiste en el reconocimiento formal de las competencias de los trabajadores independientemente de la forma y lugar en que éstas fueron enseñadas, con base en una norma de competencia laboral. Esta certificación toma cada día más importancia y es una nueva exigencia para todos los profesionales. El área de la salud no es la excepción; por el contrario, ha sido de las primeras en asumir tal dinámica.

En nuestro país la entidad encargada de certificar las competencias laborales es el SENA. Para ello realiza un proceso de evaluación que consiste en la verificación de evidencias de desempeño y conocimiento del individuo. Tal proceso se caracteriza por estar centrado en los resultados del desempeño laboral que están definidos en una norma de competencia y es voluntario e individual. Nos interesa en este espacio lo tocante a quien se desempeñe como auxiliar de enfermería. Tal ocupación posee las siguientes normas de competencia obligatorias:

- Atender y orientar a las personas en relación con sus necesidades y expectativas de acuerdo con políticas institucionales y normas.
- Admitir al usuario en la red de servicios de salud según niveles de atención y normativa.

- Controlar las infecciones de los usuarios y su entorno siguiendo las buenas prácticas sanitarias.

- Apoyar la definición del diagnóstico individual de acuerdo con guías de manejo y tecnología requerida.

- Asistir a las personas en las actividades de la vida diaria según condiciones de asignación y/o delegación del profesional, guías y protocolos.

- Participar en el cuidado a las personas para el mantenimiento y recuperación de las funciones de los diferentes sistemas por grupo etario en relación con los principios técnicos científicos y éticos.

- Brindar atención integral al individuo y la familia en cuanto al ciclo vital de acuerdo con el contexto social, político, cultural y ético.

- Generar actitudes y prácticas saludables en los ambientes de trabajo.

- Atender de manera integral al usuario en la unidad quirúrgica de acuerdo con guías de manejo y políticas.

Son normas de competencia opcionales:

- Trasladar a la persona en riesgo de salud según grado de complejidad y normas vigentes nivel 2 .

- Esterilizar productos y artículos con estándares de aseguramiento de calidad.

- Cuidar integralmente al usuario en condiciones críticas de salud según su estado de acuerdo con criterios técnico científicos vigentes.

- Atender al usuario en la unidad quirúrgica siguiendo guías de manejo y protocolos. 
- Cuidado del paciente en terapia renal según valoración del equipo interdisciplinario.

- Apoyar las actividades de salud ocupacional siguiendo con el programa diseñado en salud ocupacional y normatividad vigente.

Hoy el auxiliar de enfermería deberá ir certificando cada una de esas normas que conforman su ocupación.

El pasado 11 de junio 32 enfermeras y enfermeros de nuestra institución recibieron el certificado que los acredita como evaluadores de competencias de auxiliares de enfermería: nueve son obligatorias y seis opcionales. La actividad se desarrolló en el marco del compromiso suscrito entre el SENA y la Fundación Universitaria de Ciencias de la Salud. E1 SENA prepara a los profesionales que van a evaluar y ellos realizan este proceso en el personal auxiliar de enfermería. A quienes lo aprueben el SENA les otorga la certificación.

Lo que se pretende entonces es que las 32 personas que obtuvieron su certificado para evaluar, adelanten ese proceso con 440 auxiliares vinculadas al Hospital de San José, Hospital Infantil Universitario de San José y la Fundación Universitaria de Ciencias de la Salud. Con ello se beneficia cada una de las personas que certifique sus competencias pues alcanzará un estándar definitivo en el mercado laboral. A su vez, se beneficiarán las instituciones pues asegurarán, con este proceso, altos niveles de calidad en la prestación de los servicios certificados en sus auxiliares. Y, adicionalmente, el equipo evaluador se va a consolidar cada vez más. El resultado de tener toda esta fuerza de evaluadores y de personal certificado será, sin duda, mayor reconocimiento de la calidad de nuestras instituciones.

La dinámica de cooperación con el SENA, a partir de la experiencia con este primer grupo de evaluadores va continuar: nos preparamos para adelantar con esa entidad un acercamiento a lo que podría ser el diseño curricular por competencias. Con ello garantizamos coherencia entre la enseñanza, el aprendizaje y la evaluación.

Con todo ello ponemos en escena los lineamientos pedagógicos de la FUCS expresados en su proyecto educativo, que tienden a desarrollar en el estudiante un espíritu de conocimiento profesional acorde con las exigencias de la sociedad. Así, la FUCS pretende sensibilizar al estudiante hacia la solución de problemas de salud y orientar acciones que redunden en beneficio de la calidad de vida y de las necesidades de la comunidad a partir del análisis de la realidad, para transformarla en provecho de los usuarios de los servicios de salud, de la familia y de la comunidad.
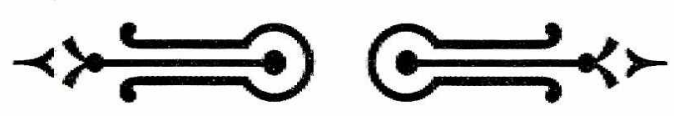